\title{
Recent Books on Music and Politics
}

\author{
COMPILED BY EUNICE SCHROEDER
}

The books listed in this column address music as it relates to political expression or focus to a significant degree on relationships between individual musicians or musical communities and a governing authority. Most of the works listed were published within the previous half year. Readers are welcome to submit additional titles to schroeder@library.ucsb.edu for possible inclusion in the next issue.

Als Bürger leben, als Halbgott sprechen: Melodram, Deklamation und Sprechgesang im wilhelminischen Reich. By Matthias Nöther. (KlangZeiten: Musik, Politik und Gesellschaft, 4.) Cologne: Böhlau, 2008. [x, 328 p. + 1 CD. ISBN 978-3-412-20097-8. €42.90.]

Braune Brüder im Geiste? Volk und Rasse bei Wagner und Hitler: Ein kritischer Schrift-Vergleich. By Alexander Schmidt. Marburg: Tectum, 2007. [110 p. ISBN 978-3-8288-9252-1. €24.90.]

Déodat de Séverac: Musical Identity in Fin de Siècle France. By Robert F. Waters. Aldershot, England: Ashgate, 2008. [xiv, 274 p. ISBN 978-0-7546-4105-6. \$114.95.]

Douce France?: Musik-Exil in Frankreich = Musiciens en exil en France, 1933-1945. By Michel Cullin and Primavera Driessen Gruber. Vienna: Böhlau, 2008. [508 p. ISBN 978-3-205-77773-1. €39.]

Einigkeit und Recht und Freiheit: Zur Rezeptionsgeschichte von Text und Melodie des Deutschlandliedes seit 1933. By Jürgen Zeichner. (PapyRossa Hochschulschriften, 76.) Cologne: Papyrossa, 2008. [247 p. ISBN 978-3-89438-399-2. €19.]

Frederick the Great and His Musicians: The Viola da Gamba Music of the Berlin School. By Michael O’Loghlin. Aldershot, England: Ashgate, 2008. [xviii, 253 p. ISBN 978-0-7546-5885-6. \$99.95.]

George F. Root, Civil War Songwriter: A Biography. By Polly Carder. Jefferson, N.C.: McFarland, 2008. [vii, 239 p. ISBN 978-0-7864-3374-2. \$45.]

Gli ultraterrestri: Musiche della rivoluzione globale. By Mario Gamba. (Virus.) Naples: Cronopio, 2008. [209 p. ISBN: 978-88-89446-37-9. €18.50.]

Guerre e pace. (Musica \& parole, 4.) Foggia: Bastogi, 2008. [120 p. ISBN 978-88-6273-076-1. €10.]

Hazel Scott: The Pioneering Journey of a Jazz Pianist from Café Society to Hollywood to HUAC. By Karen Chilton. Ann Arbor: University of Michigan Press, 2008. [xv, 277 p. ISBN 978-0-472-11567-9. \$29.95.]

Heavy Metal Islam: Rock, Resistance, and the Struggle for the Soul of Islam. By Mark LeVine. New York: Three Rivers Press, 2008. [296 p. ISBN 978-0-307-35339-9. \$13.95.]

Judenrollen: Darstellungsformen im europäischen Theater von der Restauration bis zur Zwischenkriegszeit. Edited by Hans-Peter Bayersdörfer and Jens Malte Fischer. (Conditio Judaica: Studien und Quellen zur deutsch-jüdischen Literatur- und Kulturgeschichte, 70.) Tübingen: Niemeyer, 2008. [vii, 359 p. ISBN 978-3-484-65170-8. €96.] 
Leonard Bernstein: Amiercan Original: How a Modern Renaissance Man Transformed Music and the World during His New York Philharmonic Years, 1943-1976. By Burton Bernstein and Barbara B. Haws. New York: Collins, 2008. [xviii, 223 p. ISBN 978-0-06-153786-8. \$29.95.]

Letters of Ralph Vaughan Williams, 1895-1958. Edited by Hugh Cobbe. Oxford: Oxford University Press, 2008. [xx, 679 p. ISBN 978-0-19-925797-3. \$190.00.]

Memoria, Macht, Musik: Eine politische Ökonomie der Musik in vormodernen Gesellschaften. By Boris Voigt. (Musiksoziologie, 16.) Kassel: Bärenreiter, 2008. 456 p. ISBN 978-3-7618-1366-9. €39.95.]

Music and the Making of Middle-Class Culture: A Comparative History of Nineteenth-Century Leipzig and Birmingham. By Antje Pieper. New York: Palgrave Macmillan, 2008. [xix, 214 p. ISBN 978-0-23054513-7. \$74.95.]

Music as Social Life: The Politics of Participation. By Thomas Turino. (Chicago Studies in Ethnomusicology.) Chicago: University of Chicago Press, 2008. [xviii, 258 p. + 1 CD. ISBN 978-0226-81697-5, \$55 (hbk.); 978-0-226-81698-2, \$22 (pbk.).]

Music Quickens Time. By Daniel Barenboim. London: Verso, 2008. [184 p. ISBN 978-1-84467-287-5. \$24.95.]

Musiktheater in Regensburg im Zeitalter des Immerwährenden Reichstages. By Christoph Meixner. (Musik und Theater, 3.) Sinzig: Studio Verlag, 2008. [xii, 594 p. ISBN 978-3-89564-114-5. €40.]

Musik unter politischen Vorzeichen: Parteiherrschaft und Instrumentalmusik in der DDR seit dem Mauerbau: Werk- und Kontextanalysen. By Christiane Sporn. Saarbrücken: Pfau, 2007. [458 p. ISBN 978-3-89727-367-2. €35.]

On Edge: Performance at the End of the Twentieth Century. By C. Carr. Rev. ed. Middletown, Conn.: Wesleyan University Press. [xxii, 367 p. ISBN 978-0-8195-6888-5. \$27.95.]

The People's Artist: Prokofiev's Soviet Years. By Simon Morrison. New York: Oxford University Press, 2009. [ix, 491 p. ISBN 978-0-19-518167-8. \$29.95.]

Popular Music of Vietnam: The Politics of Remembering, the Economics of Forgetting. By Dale A. Olsen. (Routledge Studies in Ethnomusicology, 1.) New York: Routledge, 2008. [xviii, 286 p. ISBN 978-0415-98886-5. \$95.]

Presidential Praise: Our Presidents and Their Hymns. By C. Edward Spann and Michael E. Williams, Sr. Macon, Ga.: Mercer University Press, 2008. [xiii, 359 p. + 1 CD. ISBN 978-0-88146-117-6. \$35.]

The Reconstruction of Lisbon: Severa's Legacy and the Fado's Rewriting of Urban History. By Michael Colvin. Lewisburg: Bucknell University Press, 2008. [131 p. ISBN 978-0-8387-5708-6. \$41.50.]

Rumba Rules: The Politics of Dance Music in Mobutu's Zaire. By Bob W. White. Durham: Duke University Press, 2008. [xxiii, 300 p. ISBN 978-0-8223-4091-1, \$84.95 (hbk.); 978-0-8223-4112-3, $\$ 23.95$ (pbk.).]

Sergey Prokofiev and His World. Edited by Simon Morrison. (Bard Music Festival Series.) Princeton: Princeton University Press, 2008. [xii, 580 p. ISBN 978-0-691-13894-7, \$65 (hbk.); 978-0-69113895-4, \$26.95 (pbk.).] 
A Shostakovich Companion. By Michael Mishra. Westport, Conn.: Praeger, 2008. [xx, 609 p. ISBN 978-0313-30503-0. \$170.]

Story behind the Protest Song: A Reference Guide to the 50 Songs That Changed the 20th Century. By Hardeep Phull. [xiii, 284 p. ISBN 978-0-313-34141-0. \$65.]

“Unser Rebbe, unser Stalin": Jiddische Lieder aus den St. Petersburger Sammlungen von Moishe Beregowski (1892-1961) und Sofia Magid (1892-1954). By Elivira Grözinger. (Jüdische Musik, 7.) Wiesbaden: Harrassowitz, 2008. [635 p. + 1 DVD. ISBN 978-3-447-05689-2. €68.]

Verstummte Stimmen: Die Vertreibung der “Juden” aus der Oper 1933 bis 1945. By Hannes Heer, Jürgen Kesting, and Peter Schmidt. Berlin: Metropol, 2008. [126 p. ISBN 978-3-938690-98-7. €16.]

Zwischen Bühne und Baracke: Lexikon der verfolgten Theater-, Film- und Musikkünstler 1933-1945. By Kay Weniger. Berlin: Metropol, 2008. [447 p. ISBN 978-3-938690-10-9. €28.] 